\title{
Representation of the image of Russia and Central Europe in the British press. The impact of media on intercultural communication in global context
}

\author{
Silvia Polakova ${ }^{1 *}$, Jozef Bruk $^{3}$, and Lenka Môcova ${ }^{2}$ \\ ${ }^{1}$ University of Zilina, Institute of Lifelong Learning, Univerzitna 1, 01026 Zilina, Slovakia \\ ${ }^{2}$ University of Zilina, Institute of Lifelong Learning, Univerzitna 1, 01026 Zilina, Slovakia \\ ${ }^{3}$ University of Zilina, Institute of Lifelong Learning, Univerzitna 1, 01026 Zilina, Slovakia
}

\begin{abstract}
Research background: Twenty-first century's sees strong globalization trends in which mass media play crucial role in shaping public opinion which might saliently impact intercultural communication on the international level.

Purpose of the article: This paper focuses on the representation of the image of Russia and Central and Eastern Europe in the British press and, besides, it sets out the role of stereotyping in intercultural communication. The article writers assume that the stereotypes play pivotal role in image shaping of a country in the media. Above all, the most efficient way to not stereotype is a straightforward communication of the participants alongside with the knowledge of the participant's background, i. e. cultural knowledge.

Drawing on the information from the British press, Russia, Central as well as Eastern Europe appears not solely as a geographical region. On the contrary, despite the fast economic, social and political development, its image abroad is still predominantly negative.

Methods: The paper, in conjunction with the cultural linguistics and cognitive approach, reveals the range of metaphorical expressions, in particular cognitive aspect of metaphors used by British journalists, which, in turn form the image of Russia in the British press.

Findings \& Value added: The paper suggests that the analysis of the image of country in the mass media might apply to the investigation of images of other countries as well as to comparative studies.
\end{abstract}

Keywords: country image; cognitive metaphor; British press; Russia; social media

JEL Classification: $L 82 ; Z 13 ; F 69 ; Z 19$

\footnotetext{
*Corresponding author: silvia.polakova@uniza.sk
} 


\section{Introduction}

The globalization trend as a major tendency is becoming nowadays a primary vector quantity in the field of communication as well as in the way of mediation of information content. The information age has brought both globalization and many other radical changes that affect all segments of social life, including the media in terms of one of the most effective ways of communicating information to a wide international environment as well. In addition, assuming media play an essential role in the digital century, they can be perceived as a distinctive phenomenon of culture that allows to influence and shape social consciousness and, furthermore, to manipulate it. On the whole, there arises a rapid development of intercommunication as an opportunity to ensure cultural contacts in their broad understanding. It should be noted, however, that the framework of cultural globalization affects the intensification of cross-border contacts and communication, and, in turn, it stimulates the desire for knowledge of other cultures using English as a lingua franca.

In fact, the media are facing new challenges in the context of the rapid increase of information exchange. As a result, a never-ending supply of information requires their filtration, processing and, perhaps the most salient, their perception.

Let us now turn to the context of information perception. Receiving of an excessive amount of information is particularly challenging for the recipients' consciousness (Dik, 1981). A burden of information forces the recipient's mind in a variety of ways to choose selectively and stay focused on the content depth of the received information. On the other hand, information sender's of (in our case, journalists) attempt to tailor their formulations in a way they are able to impact a thoughts, ideas, opinions, attitudes of recipients (readers and listeners) about the surrounding reality. It should be noted that the media have a wide range of options for the implementation of the desired function. They may use have various linguistic signs, which are of a manipulative nature. Consequently, the manipulation might result in formation of various images of the "enemy" in the social consciousness. In line with the manipulation, one of the most frequent means of the information battle for gaining the public opinion is the metaphor. Metaphors provide, on the whole a wide range of lexical tools for creating positive as well as negative images. Journalists enrich the information being sent with imagination and expressiveness and, hence enable to impact recipient profoundly.

The primary aim of the paper is identification of a metaphorical modelling of Russian image based on stereotypical ideas in the research samples. The writers examined British newspapers including popular broadsheets (The Daily Telegraph, The Guardian, The Financial Times) and tabloid (Daily Mirror, Daily Star) dailies. In general, the English media tend to personify the 'enemy' (for instance, Vladimir Putin) with aggression and threat: „He was the censor of the Russian media, the butcher of Chechnya, a total stick in the mud..." (Gessen, 2017). Considering the enemy concept above, journalists attempt to strengthen Russia's long-standing stereotype making recipients believe the country poses threat to the whole world. A similar negative perception of Russia is based on the 'Russiaaggressor" stereotype. At the same time, many stereotypes depict countries of Central Europe (e. g. Slovakia) making international impression being based on still lively historical stereotypes which refers to communism period.

From a linguistic point of view, a cognitive metaphor is the most effective means of depicting the country image. The widespread use of metaphors in journalistic texts is a necessary condition for the functioning of the language of the mass media and contributes to the implementation of the most important functions of journalism, e. i. persuasion and emotional influence (Kakorina, 2013). 
Besides, our aim was to point out the fact that above mentioned modelling of the stereotypical country image can lead to the disruption of intercultural communication. The term intercultural communication involves two components. Firstly, it is successful communication drawing on the fulfilment of the communicative aim of senders in discourse with recipient. Secondly, term 'cultural' relates towards understanding the norms, believes, attitudes and habits specific for a group of the same language (Schulze, 2018). We attend to the nexus of language and culture briefly in following section.

\section{The nature of Language and salience of cultural knowledge within the intercultural communication}

Without any doubt, knowing one's culture goes hand in hand with knowing a one's language. However, knowing of language comprises good command of vocabulary, grammatical rules being applied in it, pragmatics, and undoubtedly, the cultural background of the group speaking a particular language. Every single linguistic sign comprises according to de Saussure two levels: form (signifiant) and meaning (signifié). In this view, linguistic discipline addressing the relationship among signifiant and signifie, that is, meaning of the words is semantics. Accordingly, the same dichotomy applies congnitive linguistics. On the account of grammatical rules, pragmatics and cultural background, dichotomy of form and meaning deserves a slightly different approach in changing it into form and function. For example present continuous tense refers in grammar terms typically to an activity which participants carry out in the time of the speech. Similarly, tag questions imply the reassuring of one of the participants.

Whorf, belonging to the Boasians, states that 'linguistics is essentially the quest of MEANING' (Whorf, 1956). Despite Whorf's thesis about linguistics is in line with alignment form and meaning/function used in semantics, Boasians extended this idea in devising new approach which is nowadays designated ethnosemantics. More precisely 'ethnosmeantics covers much of what is studied in cultural and social anthropology, linguistics, history, and comparative religion' and, besides, scholars also associates the term with 'ethnoscience and cognitive anthropology' (Leavitt, 2014). Boas, the founder of the movement stated several revolutionary ideas. Firstly assumed that 'each language, from the point of view of another language, may be arbitrary in its classifications'. Secondly, 'there is nothing surprising about an important part of the environment or a crucial aspect of a people's life receiving a richer and more specific vocabulary than might be expected among people in other circumstances '(Boas, 1911). Next, he 'held that languages are systems, and that human cultures are semantic wholes, internally integrated to some degree. The existence of such wholes is revealed geographically by the transformations that given cultural elements undergo when crossing a cultural boundary'(Leavitt, 2014). The source for this fine-grained semantics will be detailed description of not only of language but as well as culture and social environment of a specific group of people. In line with this, linguists put forward an idea of vocabulary based reconstruction with respect to above mentioned fields (Frake, 1962). Similarly, another useful method appeared in approach identifying culture as knowledge which explores the most frequent forms in culture of specific language (Leavitt, 2014).

On the whole, Boasians were convinced of need to devise a sort of more specifical semantics which would be derived from general semantics. Furthermore, such a theory should set out a 'real systems of meaning' within usage based framework (Goodenough, 1956).

Our aim was to shed a light on a historical salience of the ethnosemantic approach. Nevertheless, there occurred methodological programme named Natural Semantic Metalanguage (Wierzbicka's (2014), Goddard (2014), in last few decades (Leavitt, 2014). 
Based on previous argumentation, Natural Semantic Metalanguage emerges as a vocabulary based approach drawing on huge collection of empirical data. In search for identification of semantic primitives valid across languages, scholars define it a nature of universal language that would cover all concepts, nuances and functions present, for the most part, across indigenous culture and languages (Sinha and Bernardez, 2014). For sure, European languages and culture are known to us as Europeans very well. However, there arises a problem when scholars or journalists using Western languages attempt to conceive language different from theirs, that is, exotic, indigenous or, so to say, historically or geographically rather East - oriented languages and cultures. Hence, ethnopragmatics might play key role in bridging the gap among different cultures as well as in diminishing of false interpretations at studying foreign culture (and language). Moreover, ethnopragmatics migt help in avoding of distorted views of exotic cultures. Thus, Goddard and Ye (2014) focus on accessing of 'insider perspectives' putting the emphasis on 'local categories' and 'local ways of speaking' description which are subsumed under term linguistic evidence. The foreign culture examination relies on semantic primitives (or semantic primes) having been scrutinized in thirty languages using metalanguage nor lexically neither conceptually associated with English (or language 'denaturalized of Anglo English concepts'. Wierzbicka (2014) worked out the fifty Anglo English cultural key words:

behaviour, business, challenge, commitment, common sense, communication, competition, control, culture, deadline, depression, efficiency, emotion, empirical, enjoy, entitled, evidence, experience, facts, fair, freedom, friend, frustration, fulfilment, fun, happy, humour, information, kindness, mind, opportunity, options, personal, privacy, rational, reality, reasonable, relationship, rights, rude, rule, science, security, self, sense, sex, story, suggestion, tolerance, work.

Wierzbicka argues for difficulties when attempting to find equivalents for the cultural key words across European languages, and even more, it is impossible to find matches for them in the rest of the world. Nevertheless, the precise study of the key words is beyond scope of this study. Our aim was only to shed a light on a primary issue with the Anglo English view of the world. The scholars scrutinize the specific area of vocabulary. Thus, among the most examined phrases count these lexico-semantic groups: Cultural key words, Proverbs and common sayings, Words for social and biosocial categories, Words for speech acts and genres, Terms of address, Interactional routines, Derivational morphology expressive of social meanings, Specialized lexicogrammatical constructions, Discourse particles and interjections (Goddard and Ye, 2014).

Wierzbicka's and Goddard's work contributed to the establishment of theory of cultural scripts. Cultural scripts are 'representations of cultural norms which are widely held in a given society and are reflected in the language' (Wierzbicka, 2014).

In Russian speech community, for example, words velikodušnyj and ščedryj do not match the English term generous in its full semantics. There occurs rather an overlapp among them and, furthermore, there arises a possible distortion of the Russian terms when attempting to translate them using the adjective generous. The meaning discrepancies as well as unclear sense of the generousity concept are the rationales for the engagement of Natural semantic mentalanguage approach with its comparative semantics, pragmatics and the theory of cultural scripts $[\mathrm{A}],[\mathrm{B}],[\mathrm{C}]$.

[A] A Russian cultural script

at many times, it is good if someone wants to say to someone else:

'I think like this now, I feel something because of this' (Chapter 23 Wierzbicka 2015:340)

[B] A Russian cultural script

at many times, it is good if someone wants to say to someone else:

'I think like this now' 
[C] A Russian cultural script

sometimes it is good if someone wants to say to someone else:

'I think something bad about you now' (Wierzbicka , 2014).

Thus, the cultural scripts prove Russian's preference for straightforward expression of thoughts primarily among friends.'and cultural scripts valuing, roughly speaking, unguardedness and communicative spontaneity are a salient part of Russian cultural tradition' (Wierzbicka , 2014). Let us now turn, on the contrary, to an example of the Anglo cultural script, in which usage of particle well provides a solid evidence for rather opposite phenomenon compared to the Russian straightforward expression. Consider the cultural script:

[D] An Anglo cultural script at many times, when someone wants to say something to someone else about something it is good if this someone thinks like this:

'I want to say it well because of this, I want to think about it for some time before I say it' The Anglo speakers, especially politicians, frequently use particle well to gain some time to think and shape the answer knowing that their response is recorded. Clear evidence into its functions is apparent when structures like Well, yes. But... or Well, no. But... (Wierzbicka, 2014).Such a way of speaking convincingly differs from the Russian, though in different context, in terms of tailoring the real emotions in the way they suit the message best for his/her hidden purpose.

Our aim was, for the most part, to prove that the words and situation have their cultural background or meaning typically associated with, respectively. Hence, we are convinced of the need to what extent are the ideas expressed by western journalist plausible when providing a picture of any country when there is insufficient knowledge of Russian culture.

\section{Cognitive approach to the formation of the image of the country. The role of metaphors in human thinking.}

The research of metaphor as one of the most important area of modern cognitive science surpassed, as opposed to the traditional way of perceiving metaphor such as "abbreviated comparison" or as a kind of interaction of two deep structures. Specifically, modern cognitive science (J. Lakoff, M. Johnson, A .P. Chudinov) considers metaphor as a way of knowing, structuring, evaluating and explaining the world, and, at the same time, actively participating in shaping the model of the world. For these reasons, the use of cognitive metaphor is to a great extent popular in journalism. Accordingly, in the modern theory and practice of the cognitive approach to metaphor, the well-known study of J. Lakoff and M. Johnson "Metaphors We Live By", metaphor plays an important role (Lakoff and Johnsen, 2003). In conjunction with the fact that the metaphor can also carry out a negative function in modelling the country image Georege Lakoff's words, saying 'metaphors can kill' in response to official justifications for US-led wars in the Persian Gulf. Unsurprisingly, it is the phrase that begins his famous publication Metaphor and War. The Metaphor System Used to Justify War in the Gulf (Lakoff, 1991) in which the author revealed the methods of metaphorical justification for preparing the wars of the United States and its allies against Iraq. In this publication, he presented his methodology for the study of conceptual political metaphors as well.

Current science perceives the cognitive metaphor (or cognitive political metaphor) as a tool for comprehension, modelling and evaluation if e.g. political processes and, simultaneously, as a means of influencing social consciousness. Later on, the theory of conceptual metaphor developed and theories such as theory of metaphorical modelling emerged (Chudinov, 2001).

To sum up, metaphors help us to transform the linguistic image of the world existing in the mind of the addressee. Besides, they introduce a new categorization of seemingly 
known phenomena to ideas, being thus responsible for influencing the awareness of individuals.

\section{Portraying a stereotype image of Russia by modern British press and preliminary research}

The current image of Russia is rooted in still lively historical stereotypes, some dating to the age of past times, especially to the era of the Tsarist Empire or Soviet union time period.

In general, stereotypes provide often quite stable image inherited from generation to generation. Therefore It is very difficult to separate politics and consciousness. Frequently associated with real individual facts and manifestations, they also become the basis for the formation of a whole system of mythological concepts and ideas (Sadokhin, 2014). Enormous influence of stereotypes on human consciousness addressed Lippmann in his book „Public Opinion“ (1922), in which he identifies stereotypes as ,the pictures in our heads". Accordingly, Lippmann wrote that stereotypes are so persistently passed down from generation to generation that they are often seen a reality or biological fact. Nevertheless, if personal experience contradicts the stereotype, the person, for the most part, is not interested for some reason in changing his views. The person either simply does not notice this contradiction, or considers it as an exception that confirms the rule.

Within the cognitive linguistics' framework, social groups or of individuals as prototypical representatives of these groups account for a stereotype as a standardized worldview. . At the same time, the stereotype takes the form of a judgment which, as a whole, attributes certain characteristics to a certain group of people or, on the contrary, denies them those characteristics.

Our paper carries out an exploration of linguistic modelling of the Russia image based on the stereotypical ideas through cognitive political metaphors, which British press might use purposefully to create a subjective interpretation of events. Moreover, the logic behind using metaphor as something that can be interpreted subjectively convincingly takes on pivotal role in the field of journalism. Such a combination of the country's of a country, which has already been created in the linguistic image of a nation's world, impacts saliently mass's consciousness of the people by means of the media. To put it simply, the paper focuses on a study of metaphorical models reflecting the political reality of Russia of the 21 st century.

To compile the image of Russia, writers selected two British newspapers - The Guardian and The Daily Telegraph. Hence, scholars have examined a Russophobic mood considering most of the cognitive political metaphors. Based on the preliminary research, and moreover, because of similarity of images regarding the topic and its description, we aimed to summarize the newspaper articles depicting the image of the Russian Federation in one paragraph. In virtually every article having examined, similar topics such as: „Russia is a threat", „, Russia - Dangerous country “,, Russia - aggressor “, etc. were recurring.

Especially, our attention will be drawn to one of the most widely used lexical tools for depicting stereotypes - metaphors. The writers would like to use a term "Western birth" metaphor they mention in particular following metaphors:

1. Military metaphor - "Cold War behaviour".

2. Sociomorphic metaphor - "Russia - aggressor",

3. Metaphorical portrait of the Russian President - „Putin - tsar“, „his ministers - boyars “

4. A metaphorical depiction of Russia's domestic politics - "Soviet Russia", "Russia's prerevolutionary empire"

5. Metaphorical depiction of Russia's international relations - "Putin - a salesman of Armagedon" 
Drawing on the metaphors (1-5) terms such as "aggressor", "aggression" in relation to Russia occur relatively frequently. Specifically, the metaphorical models are of emotional nature and emphasize negative ideas related to the stereotype of Russia. Typically, most articles about Russia is associated with V. V. Putin. Public image-building of Russia via media undoubtedly begins with its head, Vladimir Putin. Many British journalists assume, his role in Russia is to restore the Soviet regime and enrich himself: "... a unique historical leader of Russia - able to unite fervent advocates of the Communist-era Soviet Union with those who dream of Russia's pre-revolutionary empire, built on Orthodox Christianity, Putin as a KGB "thug" who had enriched himself" (Groskop, 2018)

An another example of in similar vein deeply rooted negative view of the heterostereotype of Russia is the idea of the head of state as a tsar, and of his entourage and ministers as boyars: „Good tsar, bad boyars [noble advisers]“ (Roth, 2018). To complete the image of a dangerous person, V. V. Putin is introduced as a salesman of Armageddon:

"Putin looked like a salesman of Armageddon" (https://www.telegraph.co.uk/news/2018/02/27/vladimir-putins-bloody-adventure-syriawill-give-no-lasting/).

In addition, most contexts in the British press seem to put forward metaphorical expressions referring to image of post-Soviet reality, i.e. in restoring Russia's special status as a „superpower": "Underlying Putin's actions is a sense of Russian exceptionalism...His attitude is rooted in the era of the dominant Soviet superpower", (Tisdall, 2018) or "When looking at Russia's actions in Ukraine, Georgia, Syria or its militarisation of the Arctic we are often told by commentators that we are dealing with a "Soviet Russia" or that what we see being done by Moscow is "Cold War behaviour". (Coffey, 2017)

Obviously, the English press pays a lot of attention to the foreign and domestic policies of the Russian Federation. However, this perception is often negative, drawing an attention to V.V. Putin (Ilyushkina and Chudinov, 2019; Solopova and Chudinov, 2018)

There appears to be clear evidence that stereotypes support the negative image of the Russia. At present, it is natural that among the studies of the visual representation of politicians in cartoons, publications dedicated to the image of heads of state and current political and economic problems dominate (Budaev and Chudinov, 2020).

Besides, Western readers might be wrong when creating an opinion about not only an average Russian citizen, but Eastern and Central Europe citizens as well. One of the reasons for stereotyping an image of the countries is, on the whole, the political system or common history. In our case, there exists explicit influence of the former Soviet Union that contributes to the shaping of stereotypical images of the countries. Unfortunately, it creates communication barriers and hinders the ability of unprejudiced international interaction.

\section{Research Methodology}

Writers' aims was to provide the comprehensive media image of Russia formed by British press and to what extent thus demonstrated image of Russia affects other countries, e.g. Slovakia. We applied the simplest sampling method - census. To examine the use of conceptual metaphor in political discourse as a primary cognitive process of acquiring knowledge in the potential impact on the influence of human consciousness, and the formation of the image of the country, the central object of the research is identification of various fields of metaphorical extension in political discourse.

The scholars extracted examples illustrating the cognitive metaphors of political discourse from the internet analogues of the English periodicals. The material for the research is the texts of mass media of the 2010s-2018s, reflecting the current social situation in Slovakia and of the 2018s (from January to April) reflecting socio-political situation in Russia. 
Since the stereotypes are immensely powerful in forming an intrinsic image of a country, they can affect the image a country on the international level as well. Therefore, one of our aims was to provide the comprehensive media image of Slovakia in the selected period applying the simplest sampling method - census. The acquired data were processed and evaluated using statistical methods - the chi-square test. Cognitive-discourse analysis and metaphorical modelling were used as the main research methods. We selected dominant metaphorical models, considering the sources and goals of metaphorical extension, which goes back to the ideas of J. Lakoff and M. Johnson.

\section{Discussion and results}

Based on the analysis of the materials, we indeed observed the British media attempt to strengthen the perception of Russia as a threat to the world. In line with the deep-rooted negative attitudes towards Russia being based on several stereotypes, the most popular stereotyping is "Russia is an aggressor".

With regard to the theme "Russia and Europe", it can be said that the ideas about Russia and the Russians, created and spread in the West, have a significant impact on other states and nations of Europe. Beside, the development of Russian Europeanism and other countries that experienced a similar historical ideology in the past are largely influenced by such ideas as well. Such a picture impacts negatively the perception of the Slovakia negatively in terms of pointing out the Post soviet countries history by Anglo centred periodicals. Therefore, Eastern Europe is not only a geographical region, on the contrary, it is a cultural zone o( $\mathrm{r}$ a region) defined by a common communist history. The clear evidences for this prove the results of content analysis determining the presence or absence of explicit placement (localisation) of Slovakia in the regions of Central Europe, Eastern Europe, Central and Eastern Europe (CEE), in newspaper articles in five online British dailies in 2010-2014.

To confirm the result validity, the chi-square statistical test was applied here.

Table 1. Localising Slovakia in British dailies (2010-2014)

\begin{tabular}{|c|c|c|c|c|c|c|}
\hline $\begin{array}{c}\text { Slovakia } \\
\text { placed in: }\end{array}$ & $\begin{array}{c}\text { Central } \\
\text { Europe }\end{array}$ & $\begin{array}{c}\text { Eastern } \\
\text { Europe }\end{array}$ & $\begin{array}{c}\text { CEE } \\
\text { or Central } \\
\text { and Eastern } \\
\text { Europe }\end{array}$ & $\begin{array}{c}\text { No } \\
\text { localisa- } \\
\text { tion }\end{array}$ & $\begin{array}{c}\text { Central } \\
\text { Europe + } \\
\text { CEE }\end{array}$ & $\begin{array}{c}\text { Central } \\
\text { Europe + } \\
\text { Eastern } \\
\text { Europe }\end{array}$ \\
\hline FT & 20 & 9 & 46 & 81 & 1 & 2 \\
\hline $\begin{array}{c}\text { Daily } \\
\text { Telegraph }\end{array}$ & 3 & 2 & 0 & 45 & 0 & 0 \\
\hline Guardian & 1 & 7 & 1 & 92 & 0 & 0 \\
\hline $\begin{array}{c}\text { Daily } \\
\text { Mirror }\end{array}$ & 0 & 1 & 0 & 42 & 0 & 0 \\
\hline Daily Star & 2 & 8 & 0 & 120 & 0 & 0 \\
\hline Total & 26 & 27 & 47 & 380 & 1 & 2 \\
\hline
\end{tabular}

Source: British Dailies (2010-2014)

Table 1 demonstrates that the majority of articles (380 out of 481) did not include any geographical localisation. The analysis revealed the use of the abbreviation CEE - Central and Eastern Europe, occurring almost exclusively in The Financial Times (1 occurrence in The Guardian). The Financial Times placed Slovakia in 46 articles in CEE, in 20 in Central and in 9 in Eastern Europe. In 3 cases Slovakia was part of CEE and Eastern Europe and $\mathrm{CEE}$ and Eastern Europe. 
The Daily Telegraph placed Slovakia 3 times into Central Europe, 2 times into Eastern Europe and 45 articles included no explicit localisation. In The Guardian, 1 case of placement of Slovakia into Central Europe and 7 cases of its placement into Eastern Europe occurred. The articles in Daily Mirror only indicated 1 case of localisation - into Eastern Europe. Daily Star placed Slovakia 2 times into Central Europe and 8 times into Eastern Europe.

Applying the statistical chi-square test, we aimed to establish a possible dependency of the article tonality and the explicit localisation of Slovakia. As the variable $p$ value was higher than $0.05(\mathrm{p}=0.145)$, we cannot claim that the localisation and tonality are dependent. We assume certain arbitrariness in placing Slovakia on the map of Europe confirms vagueness in its perception abroad. The perception of Slovakia as an Eastern European country can be understood as a highly symptomatic characteristic of its image, because we assume that this localisation can express or bear certain cultural stereotypes.

We believe that it is possible not only to consider the nature of modern Western stereotypes concerning Russia, but also to take into account their formation from antiquity to the present in order to better understand their development and implementation of an idea based on historical features and traditions.

The problem of interaction and relations between Russia and European countries has many different interpretations. We should not forget that Russia originated as a country located in Europe and Asia. Nowadays, some scientists use the term "bridge between two great civilizations - European and Asian" in relation to Russia, not only in terms of "geography" but also in terms of the cultural and historical components that shaped Russia's Eurasian territorial features. This characteristic has influenced the formation of Russian statehood since ancient times (Chubaryan, 2017; Chubaryan, 2011).

\section{Conclusion}

In the modern information society, it is difficult to overestimate the role of the media, allowing, on the one hand, people to understand complex socio-political processes. On the other hand, they impact enormously public opinion as well as ideas about individual facts occurring worldwide concerning political authorities. The current phase of society's development constitute the basic processes of categorization and evaluation of modern reality, various possibilities of interpretation of political and cultural phenomena, formation of the national image of the world, perception of other linguacultural features of lexical units, and like, that find their application in the media space (Dulebova and Kryukova, 2017).

To sum up, the paper addresses the problem of the ethnic stereotype "Russia" in the English-speaking media. Based on the research, we can confirm that the British media is trying to strengthen Russia's centuries-old stereotype as a threat to the whole world. Such a negative view of Russia is primarily based on the stereotype "Russia is the aggressor." The article analyses the metaphorical modelling of the Russia image based on stereotypical ideas.

A stereotype can be both true and false, turning into prejudice. Therefore, stereotypes are often used in propaganda to influence the mass consciousness in journalism. It should be noted that the ethnic stereotype "Russia" is used by English journalists through metaphorical models (for instance, "The President of Russia is the Tsar") for propaganda purposes to spread a negative image of Russia. The skill of effective communication with the recipient belonging to foreign culture in his or her mother tongue is, ultimately, a demanding task. Its successful achievement requires the cultural (or linguacultural) knowledge involved in various discourse types (Obdalova and Odegova, 2014). 
In addition, scholars proved that combination of the stereotype of a country, already created in the linguistic image of a nation's world, alongside with the image created by the media, significantly increases the mechanism of influence on the mass consciousness. The negative image of Russia abroad, especially in popular culture, is still predominantly negative. Convincingly, such a view effects negatively the international communication which post communist countries, Slovakia among others, are exposed to.

\section{References}

1. Boas, F. (1911). Introduction. Handbook of american Indian languages.

2. Budaev, E.V., \& Chudinov, A. P. (2020). Contemporary Russian political metaphorology (2011-2020). Philological call, 25(2), 103-113.

3. Coffey, L. (2017, January 18). Without America Britain must lead standing Tsar Putins new imperial. Available at: https://www.telegraph.co.uk/news/2017/01/18/withoutamerica-britain-must-lead-standing-tsar-putins-new-imperial

4. Dik, S.C. (1981). Functional Grammar. De Gruyter.

5. Dulebova, I., \& Kryukova, L. (2017). Precedent names of the Russian culture and history in modern Slovak media. Vestnik Tomskogo gosudarstvennogo universiteta Tomsk State University Journal, 425, 19-25.

6. Frake, C.O. (1962). The ethnographic study of cognitive systems. Anthropology and Human Behavior, 72-85.

7. Gessen, K. (2017, February 22). Russia's role in Trump's election has led to a boom in Putinology. But do all these theories say more about us than Putin? Available at: https://www.theguardian.com/world/2017/feb/22/vladimir-putin-killer-geniuskleptocrat-spy-myths

8. Goddard, C., \& Ye, Z. (2014). Ethnopragmatics. Routledge.

9. Goodenough, W., A. (1956). Componential Analysis and the Study of Meaning. Language, 32(1). 195-216.

10. Groskop, V. (2018, March 26). Russian stereotypes hurt ordinary people - and play into Putin's hands. Available at: https://www.theguardian.com/commentisfree/2018/mar/26/russian-stereotypes-putinskripal.

11. Chubaryan, A. (2017). Russia and Europe: a view to the future in the context of the past and the present. Dialog so vremenem-Dialogue with time journal, 59, 43-53.

12. Chubaryan A. O. (2011). Stereotipy i obrazy Rossii v evropejskom myshlenii i massovom soznanii. Fenomen identichnosti v sovremennom gumanitarnom znamii: k 70-letiju akademika V.A. Tishkova, sost.M.N.Guboglo, N.A. Dubova, Institut etnologii i antropologii im.N.N.Miklucho-Maklaja RAN. M.,Nauka.

13. Chudinov, A. P. (2001). Russia in the metaphorical mirror: a Cognitive study of political metaphor (1991-2000): a monograph. Ural State Pedagogical University.

14. Ilyushkina, M., \& Chudinov, A. (2019). Metaphorical modeling of Russia's image in the mass media: The case of American press. Yazyk i kultura - Language and culture, Issue, 45, 20-30.

15. Kakorina, E. V. (2013). Internet Metaphors in the speech of computer users. Man and language in the communicative space: collection of scientific articles, Krasnoyarsk, Siberian Federal University, 145-150.

16. Lakoff, G., \& Johnsen, M. (2003). Metaphors we live by. University of Chicago Press. 
17. Lakoff, G. (1991). Metaphor and War: The Metaphor System Used to Justify War in the Gulf. Peace Research, 23, 25-32.

18. Leavitt, J. (2014). Ethnosemantics. The Routledge Handbook of Language and Culture, Imprint Routledge.

19. Obdalova, O.A, \& Odegova, O.V (2014). Intercultural and Inerlingual communication as a new reality in the context of globalisation. Vestnik Tomskogo gosudarstvennogo universiteta - Tomsk State University Journal, 44, 70-81.

20. Roth, A. (2018, March 30). Russian protesters kick up a stink about landfill - but not against Putin. Available at : https://www.theguardian.com/world/2018/mar/30/russianprotesters-kick-up-a-stink-landfill-putin

21. Sadokhin, A. P. (2014). Vvedenie v teoriju mezhkul'turnoy kommunikacii. Uchebnoe posobiye. KNORUS.

22. Schulze, W. (2018). Caucasian Albanian and the Question of Language and Ethnicity. Sprachen, Völker und Phantome.

23. Sinha, CH., \& Bernardez, E. (2014). Space, time, and space-time: metaphors, maps, and fusions. Routledge.

24. Solopova, O. A., \& Chudinov, A. P. (2018). Diachronic analysis of political metaphors in the british corpus: From victory bells to Russia's vday. Russian Journal of Linguistics, 22(2), 313-337.

25. Tisdall, S. (2018, March 14). May can’t rely on Trump and Europe against Russia and Putin knows it. Available at: https://www.theguardian.com/commentisfree/2018/mar/14/may-trump-europe-russiaputin-skripal.

26. Whorf, B.L. (1956). Language, thought, and reality: selected writings. Technology Press of Massachusetts Institute of Technology.

27. Wierzbicka, A. (2014). Imprisoned in English: The Hazards of English as a Default Language. Oxford University Press. 